\title{
Anesthetic Management of Apert Syndrome: A Case Report
}

\author{
Megha Koirala, Gentle S Shrestha, Pankaj Joshi, Bashu D Parajuli
}

\section{Author(s) affiliation \\ 'Department of Anesthesiology, Maharajgunj Medical Campus, Tribhuvan University Teaching Hospital, Institute of Medicine, Maharajgunj, Kathmandu, Nepal \\ Corresponding author \\ Gentle S Shrestha, MD, FACC gentlesunder@hotmail.com}

\section{Submitted}

Jan 10, 2021

\section{Accepted}

Mar 16, 2021

\begin{abstract}
Apert syndrome is a rare autosomal dominant disease associated with abnormalities of skull, face and limbs. These patients present for different types of surgeries. To the anesthesiologists, they pose special challenge during airway management, manifesting as difficulty in bag-mask ventilation and increased incidence of airway obstruction. Here, we report a case of a child with Apert syndrome undergoing syndactyly release under general anesthesia, in whom severe bronchospasm and a failed bag-mask ventilation occurred during the emergence of anesthesia requiring re-insertion of laryngeal mask airway.
\end{abstract}

\section{Keywords}

Anesthetic management, Apert syndrome

\section{INTRODUCTION}

pert ayndrome is a rare congenital autosomal dominant disease
occurring due to fibroblast growth factor receptor 2 genetic
defect in chromosome 10 resulting in craniofacial and limbs
malformation. ${ }^{1}$ It was first described by a French pediatrician, Eugene
Apert and occurs in 1:160000 live births. ${ }^{2}$ Due to prevention of
apoptosis of cells, these malformations present as a premature fusion
of cranial sutures resulting in craniosynostosis and fusion (cutaneous
and/or bony) of both hands and feet. The characteristic features
include brachycephaly, mid face hypoplasia, hypertelorism, exorbitism
and syndactyly of hands and feet. These children mainly present to
the operation theatre for the release of syndactyly, craniosynostosis
correction, dental and orthopedic surgeries. The major challenge for the
anesthesiologist is during airway management.

\section{CASE PRESENTATION}

A 9-year-old female child weighing $20 \mathrm{~kg}$, with the characteristic features of Apert syndrome (Figure 1-4) presented for the release of syndactyly of left hand. She had brachycephaly, mid face hypoplasia, depressed nasal bridge, slightly hypoplastic chin, hypertelorism and exorbitism. 


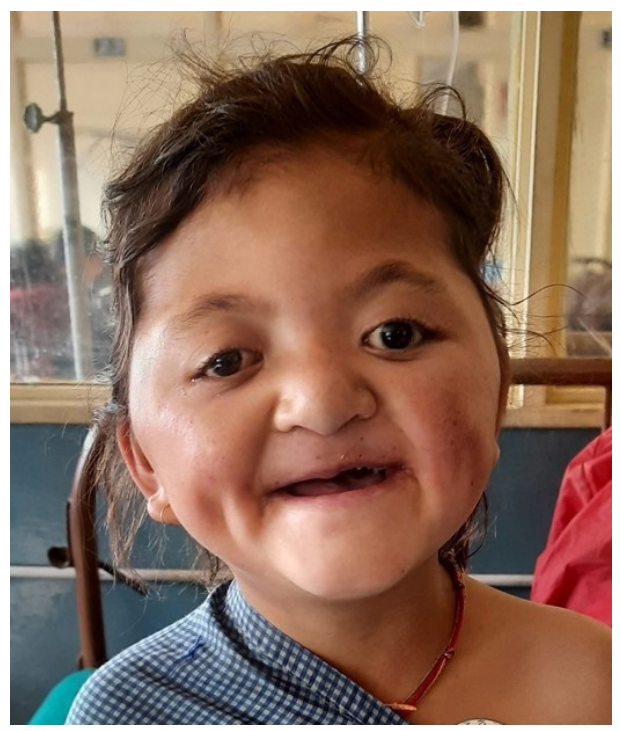

Fig 1. Picture showing brachycephaly, mid face hypoplasia, hypertelorism and depressed nasal bridge

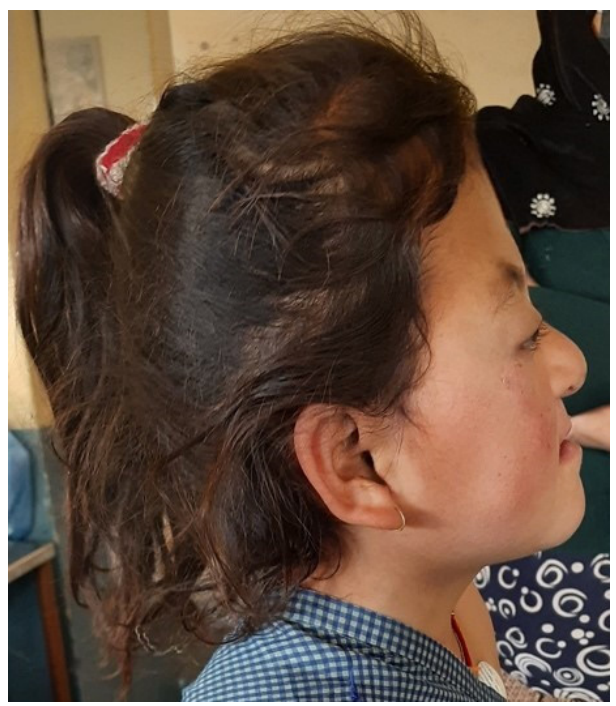

Fig 2. Picture showing hypoplastic chin

She had a normal birth history and had normal developmental milestones. She had no features of raised intracranial pressure. She had the history of prior two surgeries for the syndactyly of right hand and the documents related to anesthetic management were not available. There was no history of snoring or any features suggestive of obstructive sleep apnea. Her airway examination revealed a high arched palate, slightly hypoplastic chin and misalignment of multiple teeth. Her all laboratory investigation reports were within normal limits.

An intravenous access was secured in right hand and patient was premedicated with glycopyrrolate $0.1 \mathrm{mg}, 30 \mathrm{mins}$ before the surgery. Patient was preoxygenated, followed by administration ofinj Fentanyl $30 \mathrm{mcg}$. Patient was induced with propofol $60 \mathrm{mg}$ followed by an insertion of size 2.5 laryngeal

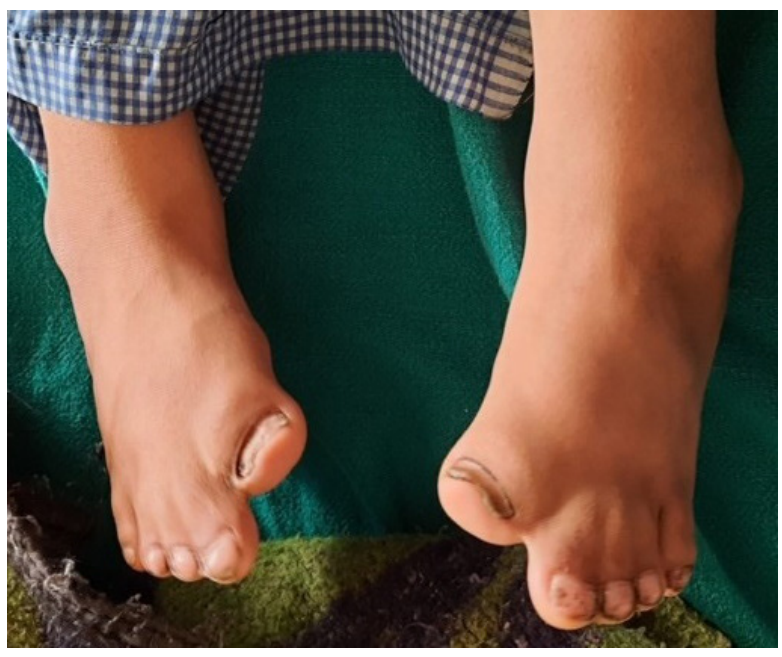

Fig 3. Picture showing syndactyly of feet

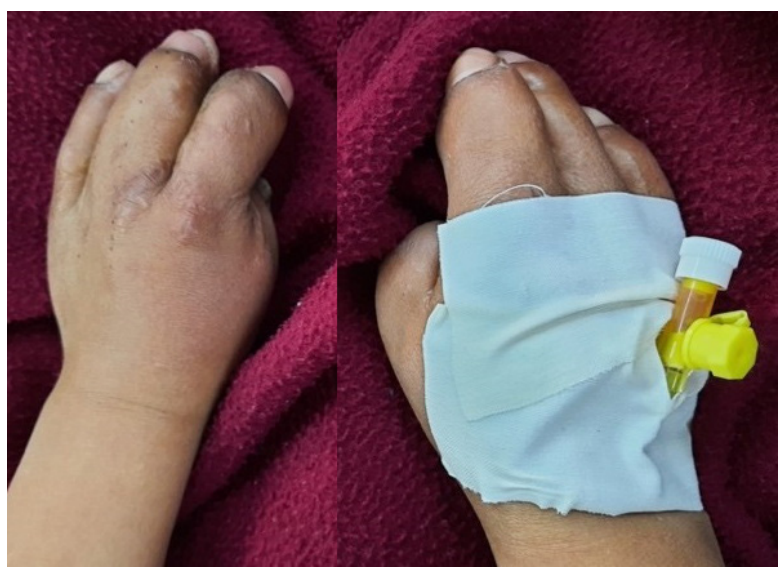

Fig 4. Picture showing syndactyly of hands (intravenous cannula in situ in the right hand)

mask airway (LMA). Anesthesia was maintained with Isoflurane, and with spontaneous breathing. Intraoperative temperature monitoring was done using nasopharyngeal temperature probe. Patient received intravenous paracetamol $300 \mathrm{mg}$, and a wrist block with $0.25 \%$ bupivacaine $(6 \mathrm{ml})$ at the end of surgery. After completion of surgery, LMA was removed with patient in deeper plane of anesthesia. Spontaneous ventilation was inadequate, so bag-mask ventilation with Guedel's airway was attempted in conjunction with triple airway maneuver. Airway obstruction was not relieved even with continuous airway pressure, leading to drop in oxygen saturation. Patient was re-induced with propofol $20 \mathrm{mg}$ and LMA was re-inserted. Upon auscultation there was severe bronchospasm for which we administered salbutamol puffs via LMA and injectable hydrocortisone $50 \mathrm{mg}$. The bronchospasm relieved slowly, followed by normalization of oxygen saturation. After assuring adequate ventilation and with patient fully conscious, LMA was removed. The subsequent emergence from anesthesia was uneventful. 


\section{DISCUSSION}

Though a rare entity, patients with Apert syndrome may be encountered multiple times in the operation theatre, being posted for corrective surgeries. The venous access may be difficult due to the operating field being the limb itself, or due to multiple previous surgeries or deformed limb. In our case the syndactyly release was planned in left hand so we had an access in right hand.

These patients may have associated cardiac anomalies, so if a history is suggestive, echocardiography should be done preoperatively. Since our patient had a good functional status, we assumed her to have normal cardiac function.

The most commonly encountered complications is related to airway during induction and emergence of anesthesia. ${ }^{3-4}$ History of obstructive sleep apnoea (OSA) is suggestive of difficult airway. Due to mid facial hypoplasia, airway obstruction occurs frequently. In our case after removal of LMA, there was an airway obstruction which could not be managed with airway maneuvers or oropharyngeal airways. Ventilation could only be possible after the insertion of a supraglottic airway device. Mid facial hypoplasia and the associated anatomical alternations might have caused failed ventilation during the deep plane of anesthesia, compounded by associated bronchospasm. Bronchospasm has been reported to occur in such patients due to excessive secretion and inability to clear the secretions. In our patient, we had premedicated with antisialogogue. Excessive secretion leading to blockage of tube have been reported previously. ${ }^{5}$ In our experience, when oropharyngeal airways and airway maneuver techniques fail to maintaina patent airway, a supraglottic airway device can be helpful. Always keeping an LMA of appropriate size standby, would be prudent. Choanal stenosis may be present in such patients precluding insertion

Table 1. Anesthetic concerns in patients with Apert Syndrome.

\begin{tabular}{|c|c|c|}
\hline Anesthetic concern & Cause & Implications \\
\hline $\begin{array}{l}\text { Difficult bag mask } \\
\text { ventilation }\end{array}$ & Mid face hypoplasia & Use of airway adjuncts, LMA \\
\hline Airway obstruction & $\begin{array}{l}\text { Mid face hypoplasia, high incidence of } \\
\text { OSA }\end{array}$ & $\begin{array}{l}\text { Use of airway adjuncts, } \\
\text { multimodal analgesia, lesser } \\
\text { dose of opioid, use of regional } \\
\text { anesthesia whenever possible }\end{array}$ \\
\hline $\begin{array}{l}\text { Difficulty in inserting } \\
\text { nasopharyngeal airway }\end{array}$ & $\begin{array}{l}\text { Choanal atresia, reduced nasopharyngeal } \\
\text { volume. }\end{array}$ & $\begin{array}{l}\text { Avoidance or use of a smaller } \\
\text { airway }\end{array}$ \\
\hline \multirow[t]{2}{*}{ Difficult intubation } & Fusion of C5-C6 spine & Difficult intubation cart \\
\hline & Bamboo trachea & Smaller size ETT \\
\hline Bronchospasm & $\begin{array}{l}\text { Increased secretion, increased airway } \\
\text { susceptibility }\end{array}$ & $\begin{array}{l}\text { Premedication with } \\
\text { antisialogogues, reduced airway } \\
\text { instrumentation }\end{array}$ \\
\hline \multirow[t]{2}{*}{ Difficult venous access } & Surgery in the limbs, multiple surgeries & $\begin{array}{l}\text { Staged operation, intraosseous } \\
\text { needle }\end{array}$ \\
\hline & & $\begin{array}{l}\text { Dressing without intravenous } \\
\text { access }\end{array}$ \\
\hline $\begin{array}{l}\text { Difficult regional } \\
\text { anesthesia }\end{array}$ & $\begin{array}{l}\text { Abnormal anatomy of shoulder, limited } \\
\text { abduction of upper arm }\end{array}$ & Use of ultrasound guided block \\
\hline $\begin{array}{l}\text { Increased intracranial } \\
\text { pressure }\end{array}$ & $\begin{array}{l}\text { Ongoing brain growth despite fusion of } \\
\text { suture }\end{array}$ & $\begin{array}{l}\text { Proper history and examination, } \\
\text { avoidance of drugs maneuvers } \\
\text { that increase ICP }\end{array}$ \\
\hline Eye injury & Exorbitism (inability of total eyelid closure) & $\begin{array}{l}\text { Ensure well lubrication, taping } \\
\text { and padding of eye }\end{array}$ \\
\hline Cardiac risk & Cardiac anomalies & $\begin{array}{l}\text { Proper history, echocardiography } \\
\text { if required }\end{array}$ \\
\hline $\begin{array}{l}\text { Temperature } \\
\text { regulation }\end{array}$ & $\begin{array}{l}\text { Excessive sweating increased chance of } \\
\text { hyperpyrexia }\end{array}$ & Temperature monitoring \\
\hline
\end{tabular}


of nasopharyngeal airway. Forceful insertion may traumatize and should be avoided. The cervical vertebre may be fused at varying levels leading to limited neck mobility and cause difficulty in intubation. ${ }^{6}$ Tracheal anomalies have also been reported. ${ }^{7}$ Trachea is defined to be like a bamboo requiring a smaller than anticipated ETT during intubation.

Opioids may worsen airway obstruction, thus multimodal analgesic technique should be used to decrease the perioperative opioid requirement. We used paracetamol and wrist block for the purpose of decreasing the dose of fentanyl. Regional anesthesia may be challenging because of abnormal anatomy of shoulder joint and ultrasound may be a useful aid. ${ }^{3}$ These patients may have protruded eyes with incomplete lid closure. In order to prevent eye injury, proper eye taping and use of eye lubricant is recommended. Also, these patients tend develop intraoperative hyperthermia if active warming is done. So, temperature monitoring should always be done.

Features of raised intracranial pressure should always be looked for as they have premature suture closure. ${ }^{8}$ Sometimes it is difficult to insert a pulse oximeter due to total fusion of all the fingers.

The anesthetic concerns and its implications are tabulated in Table 1.

\section{CONCLUSION}

In conclusion, a proper anesthetic plan to deal with airway complications is a must whenever we are anesthetizing a case of Apert syndrome for whatsoever surgery.

\section{CONSENT}

Informed consent was was obtained from the mother of the patient for publication of this case report and accompanying images.

\section{CONFLICT OF INTEREST}

None declared.

\section{REFERENCES}

1. Usta A, Usta CS, Yildiz A et al. Frequency of fetal macrosomia and the associated risk factors in pregnancies without gestational diabetes mellitus. Pan Afr Med J. 2017;26.

2. Wilkie $A O$, Slaney SF, Oldridge $M$, et al. Apert syndrome results from localized mutations of FGFR2 and is allelic with Crouzon syndrome. Nat Genet. 1995;9(2):165-72.

3. Cohen MM, Kreiborg S. New indirect method for estimating the birth prevalence of the Apert's syndrome. Int J Oral Maxillofac Surg. 1992;21:107-9.

4. Barnett S, Moloney C, Bingham R. Perioperative complications in children with Apert Syndrome: A review of 509 anesthetics. PediatrAnesth. 2011;21:72-7.

5. Elwood T, Sarathy PV, Geidushek JM, et al.Respiratory complications during anesthesia in Apert syndrome. PediatrAnesth. 2001;11(6):701-3

6. Basar H, Buyukkocak U, Kaymak C, et al. An intraoperative unexpected respiratory problem in a patient with Apert Syndrome. Minerva Anestesiol. 2007;73(11):603-6.

7. Kreiborg S, Barr M, Cohen MM. Cervical Spine in the Apert Syndrome. Am J Med Genet. 1992;43(4):704-8.

8. Hutson LR, Young E, Guarisco L. Tracheal anomalies complicating ventilation of an infant with Apert syndrome. J ClinAnesth. 2007:19:551-4.

9. Marucci DD, Dunaway DJ, Jones BM, et al. Raised intracranial pressure in Apert Syndrome. Plast Reconstr Surg. 2008;122(4):11628. 